\title{
Up-regulation of miR-9 expression predicate advanced clinicopathological features and poor prognosis in patients with hepatocellular carcinoma
}

\author{
Lizhi Cai ${ }^{*}$ and Xi Cai ${ }^{2}$
}

\begin{abstract}
Background: MicroRNAs (miRNAs) are endogenous small (19-24 nt long) noncoding RNAs that regulate gene expression in a sequence specific manner. An increasing association between miRNA and cancer has been recently reported. Hepatocellular carcinoma (HCC), as the fifth most common cancer and the most common cause of death in men, has become the third leading cause of cancer-related deaths globally. In this study, we investigated the miR-9 expression in HCC to evaluate their value in prognosis of this tumor.
\end{abstract}

Methods: The expression of miR-9 in matched normal and tumor tissues of HCC was evaluated using a quantitative real-time RT-PCR. A Kaplan-Meier survival curve was generated following a log-rank test.

Results: It was observed that miR-9 expression was upregulated in HCC tissues compared with noncancerous liver tissues $(7.26 \pm 1.30$ vs. $3.14 \pm 1.08, P<0.001)$. The up-regulation of miR-9 in HCC cancer tissues was also significantly correlated with aggressive clinicopathological features. We found that the patients with high miR-9 expression have a higher tumor staging $(P=0.0389)$ and are in higher risk of venous infiltration $(P<0.0001)$. Moreover, the results of Kaplan-Meier analyses showed that HCC patients with the high miR-9 expression tend to have shorter overall survival $(\mathrm{P}<0.0001)$. The multivariate analysis clearly indicated that the high miR-9 expression in biopsy samples may be considered as an independent prognostic factor in HCC for decreased survival $(4.28 ; 95 \% \mathrm{Cl}, 2.77-7.23, \mathrm{P}<0.001)$.

Conclusion: Our data indicate the potential of miR-9 as a novel prognostic biomarker for HCC. Large well-designed studies with diverse populations and functional evaluations are warranted to confirm and extend our findings.

Virtual Slides: The virtual slide(s) for this article can be found here: http:/www.diagnosticpathology.diagnomx.eu/vs/ 13000_2014_228

\section{Background}

Hepatocellular carcinoma (HCC) has become the third leading cause of cancer-related deaths globally [1]. The incidence of HCC is still increasing in the developing countries, especially in East and South-East Asia, with the highest reported primary liver cancer rates. Annually, more than 700,000 new cases are diagnosed worldwide and unfortunately more than 600,000 cases dead due to this cancer [2]. The five-year survival rate of this cancer is

\footnotetext{
* Correspondence: Izcai_2014@163.com

'Department of Hepatobiliary Surgery, Jingzhou First People's Hospital/The First Affiliated Hospital of Yangtze University, No.8 Hangkong Road, Shashi district, Jingzhou 434000, Hubei, China

Full list of author information is available at the end of the article
}

merely 7\% [3]. The development and progression of HCC is a multistage process involving the deregulation of genes that are crucial to cellular processes, such as cell cycle control, cell growth, apoptosis and cell migration. HCC is highly lethal because of its aggressive metastasis and an advanced stage at the time of diagnosis. The occurrence of HCC is a multi-factor and multi-stage process, including both hereditary and environmental factors. Since the diagnosis at early stage of HCC offers the only hope for curative therapies, it is of utmost importance to screen high-risk patients effectively. With the increasing understanding of tumor biology of HCC, recent studies have 
identified more and more molecular markers with high sensitivity and specificity for diagnosis and prognosis in patients with HCC.

MicroRNA (miRNA) belongs to a class of endogenously expressed, non-coding small RNA and contains about 22 nucleotides, which exhibits a high degree conservation of structure and function in metazoa. They exist in two forms of pre-miRNAs and mature miRNAs, and only the mature miRNAs mediated by the two RNase III endonucleases Dicer and Drosha play a key biological role [4]. The mature miRNAs inhibit protein translation through binding the 3 '-untranslated region (3'-UTR) of target mRNA partly, while they induce target mRNA cleavage through binding mRNA with perfect complementarity [5,6]. At present, approximately 450 miRNAs have been cloned in mammalian cells, and it is believed that up to 1,000 miRNAs genes exist $[7,8]$. Moreover, it is estimated that $30 \%$ genes of the human genome are regulated by miRNAs [9]. Though the biological functions of a small amount of identified miRNAs are elucidated, miRNAs have been proved to be important for cell growth, differentiation, and apoptosis $[10,11]$. miRNAs also regulate oncogenesis because they are both oncogenic and tumor suppressors. miRNAs regulate posttranscriptional expression of target genes involved in any biological processes including development, differentiation, cell proliferation, apoptosis, and the stress response [12]. In addition, miRNAs are involved in cancer development and progression and are differentially expressed in normal tissues and cancers.

MiR-9 is a regulator of neuronal progenitor cell fate during neurogenesis $[13,14]$, which has recently been implicated in cancer [15]. Although most studies indicate a tumour-suppressor activity for miR-9 in cancer cells [16], conflicting data exist, and the outcome of miR-9 function appears to be tumour specific [17]. miR9 is downregulated in breast cancer, renal cell carcinoma, and gastric cancer due to promoter methylation [18-20]. In contrast, miR-9 has been found to be upregulated in gliomas and in colorectal cancer [21,22]. Recent studies also report that miR-9 is heterogeneously expressed within a given tissue [23]. miR-9 has also recently been shown to be associated with metastasis formation in several cancer types, such as breast, colon, ovarian, cervix, liver, and gastric cancer [16,22,24-26]. Recent studies have shown that miR-9 promotes metastasis formation [22,24,26], however, in contrast, other studies have suggested that increased expression of miR9 suppresses metastasis formation $[16,25]$ and that miR9 inhibits tumor growth through inhibition of NFkappa B1 $[27,28]$. Therefore, miR-9 might have different functions in different cancers. In this study, we investigated the miR-9 expression in HCC tissues to evaluate their value in prognosis of this tumor.

\section{Methods}

\section{Samples and cases}

200 pairs of samples (including $200 \mathrm{HCC}$ samples and normal adjacent tissues) from HCC patients were collected from April 2004 to April 2009 at the first affiliated hospital of Yangtze University. None of the patients recruited in this study had chemotherapy or radiotherapy before the surgery. The miR-9 quantitative analysis was performed with those samples via real-time PCR. The study was approved by the first affiliated hospital of Yangtze University. Written informed consent was obtained for the acquisition and use of patient tissue samples and anonymized clinical data.

The diagnosis and histological grade of each case were confirmed by two pathologists independently. The clinical stage was classified according to the Edmondson grading system. Liver function was assessed using the Child-Pugh scoring system. Tumor staging was determined according to the Union for International Cancer Control (UICC) criteria (7th Edition) and WHO classification (Pathology and Genetics of Tumors of the Digestive System). Tumor differentiation was defined as poor, moderate, and well according to the Edmondson grading system (Figure 1).

\section{RNA extraction}

For real-time PCR analysis of miRNA, total RNA was isolated using Trizol reagent (Invitrogen) according to the manufacturer's instructions. Briefly, plugs were punched out $(1.5 \mathrm{~mm} \times 1.5 \mathrm{~mm})$ of a paraffin block. Samples were deparaffinized three times in $1 \mathrm{~mL}$ ACS
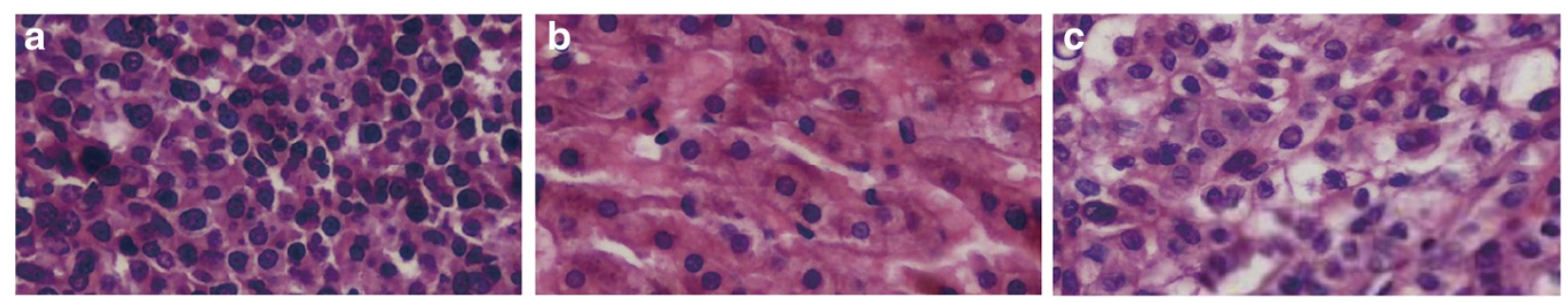

Figure 1 Tumor differentiation according to the Edmondson grading system. Poor differentiation (a); Moderate (b); and Well (c) 
grade xylene with incubation at $60^{\circ} \mathrm{C}$ for $10 \mathrm{~min}$, followed by a wash with $100 \%$ ACS grade ethanol and air drying at room temperature. Samples were then incubated with proteinase $\mathrm{K}$ (Merck) at $55^{\circ} \mathrm{C}$ overnight, shaking every $2 \mathrm{~h}$. RNA samples were resuspended in RNase-free water after the final precipitation step. RNA quality and quantity were assessed using a biophotometer (Eppendorf). The paraffin plugs were enriched for tumor tissue under microscope control using $\mathrm{H}$ \& Estained sections of the same sample for guidance.

The RNA concentration and purity were assessed by UV spectrophotometry (A260/A280 ratio of 1.8 - 2.0). Total RNA samples were reverse transcribed to cDNA using a TaqMan ${ }^{\circ}$ microRNA assay miRNA-specific stemloop primer and the TaqMan microRNA Reverse Transcription Kit (Applied Biosystems, Foster City, CA, USA). The PCR was performed using the TaqMan ${ }^{\circ}$ Universal PCR Master Mix and a 7500 Sequence Detection System (Applied Biosystems) according to the manufacturer's instructions, and previously published primer sequences [29]. The cycling programme involved preliminary denaturation at $95^{\circ} \mathrm{C}$ for $10 \mathrm{~min}$, followed by
40 cycles of denaturation at $95^{\circ} \mathrm{C}$ for $15 \mathrm{~s}$, annealing at $60^{\circ} \mathrm{C}$ for $60 \mathrm{~s}$ and elongation at $60^{\circ} \mathrm{C}$ for $60 \mathrm{~s}$. The U6 small nuclear (sn) RNA was amplified as an internal control using previously published primer sequences. Each sample was analysed in triplicate. Levels of miR-9 were analysed quantitatively relative to U6 snRNA by the $2^{-\Delta \Delta \mathrm{CT}}$ method using the equation, relative quantity $=2^{-\Delta \Delta \mathrm{CT}}$, where $\Delta \Delta \mathrm{CT}=\left(\mathrm{CT}^{\mathrm{miR}-21}-\mathrm{CT}^{\mathrm{U} 6}\right)_{\text {cancer }^{-}}$

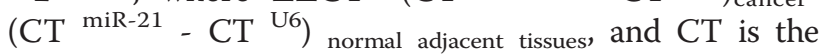
cycle threshold for each specimen.

\section{Statistical analyses}

To analyze baseline characteristics, the continuous variables was presented as Mean \pm SD and compared between groups by the Student's t-tests, and the categorical data compared by Chi-square tests. Associations between miR9 expression and over survival of the patients with HCC were estimated using adjusted relative risks and 95\% confidence intervals $(95 \% \mathrm{CIs})$ from multivariate logistic regression. Survival time was calculated from the date of HCC diagnosis to the date of death or last follow-up. Survival analysis was estimated using the Kaplan-Meier method,
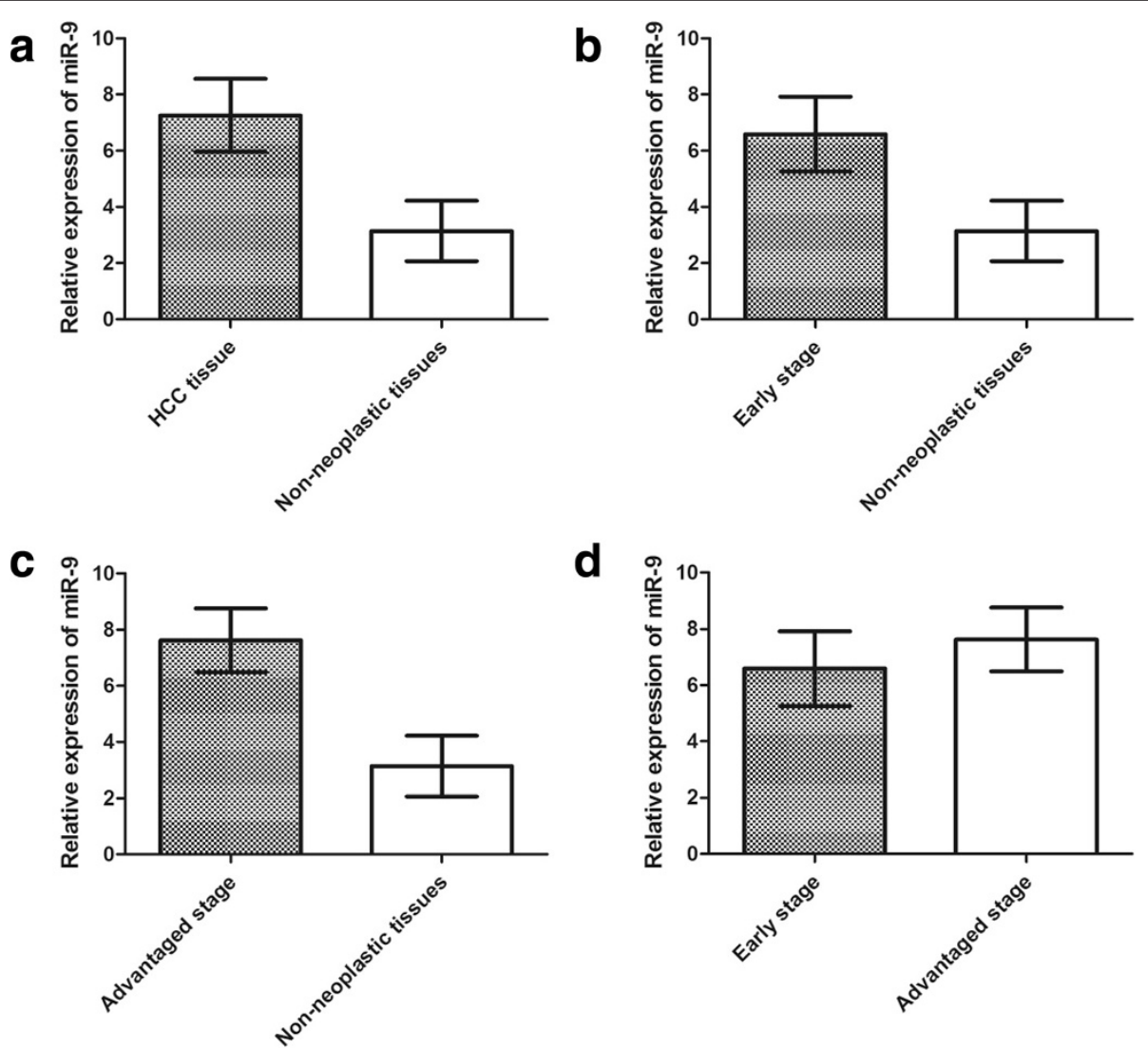

Figure 2 miR-9 expression in $\mathbf{2 0 0}$ pairs of HCC and adjacent non-neoplatic liver tissues detected by quantitative real-time polymerase chain reaction (qRT-PCR) analysis. (a) Comparison between all the HCC tissues and non-neoplastic tissues. (b) Comparison between early stage HCC tissues and non-neoplastic tissues. (c) Comparison between advantaged stage HCC tissues and non-neoplastic tissues. (d) Comparison between early and advantaged stage HCC tissues. 
log-rank test, and Cox-proportional hazards regression model. The $\mathrm{P}<0.05$ was considered to indicate a statistically significant difference. The software of SPSS version13.0 for Windows (SPSS, Inc., Chicago, IL) was used for statistical analysis.

\section{Results}

\section{MiR-9 expression in HCC tissues}

MiR-9 expression was detected in 200 pairs of HCC tissues and adjacent non-neoplastic liver tissues normalized to RNU6B. As shown in Figure 1, we found that the expression of miR-9 was markedly increased in $\mathrm{HCC}$ tissues compared with non-neoplastic liver tissues (mean $\pm \mathrm{SD}: 7.26 \pm 1.30$ vs. $3.14 \pm 1.08, \quad \mathrm{P}<$ 0.001 , Figure 2a). In addition, miR-9 expression in early stage $(6.59 \pm 1.33)$ and advanced stage $(7.68 \pm$ 1.13) HCC tissues were both significantly higher than that in non-neoplastic liver tissues $(3.14 \pm 1.08$; $\mathrm{P}<0.0001$ and $<0.0001$, respectively, Figure $2 b$ and $c$ ). There was also a significant difference in miR-9 expression between early stage and advanced stage $\mathrm{HCC}$ tissue specimens $(\mathrm{P}<0.001$, Figure $2 \mathrm{~d})$.

\section{Expression of miR-9 and clinicopathological features}

We then analyzed the association between miR-9 expression and clinicopathological parameters in HCC. HCC tissues expressing miR-9 at levels less than the median expression level (7.293) were assigned to the low expression group (mean expression value $6.22, \mathrm{n}=100$ ), and those samples with expression above the median value were assigned to the high expression group (mean expression value $8.30, n=100$ ). The high level of miR-9 expression was significantly more common in HCC tissues with advanced pathologic grade than those with low pathologic grade $(\mathrm{P}=0.0389$, Table 1$)$. Besides, miR-9 up-regulation group has a higher rate of venous infiltration $(\mathrm{P}<0.0001)$. In this study, no significant association between miR-9 expression and tumor size was detected $(\mathrm{P}=0.252)$. When the AFP status was considered, the expression of miR-9 was not different among the high and low level status $(P=0.127)$. No significant association was found between miR-9 expression and gender or age at diagnosis.

\section{MiR-9 expression and survival in patients with HCC}

In the 5 years' follow-up, the association between miR-9 expression and prognosis was detected using Kaplan-Meier method and log-rank test. The overall survival of HCC patients with high miR-9 expression was significantly shorter than that with low miR-9 expression $(\mathrm{P}<0.0001$, Figure $3 \mathrm{a})$. When the pathological stages were considered, the higher miR-9 expression was a risk of poor prognosis in both the early
Table 1 Correlation of miR-9 expression with clinicopathological features of HCC $(n=200)$

\begin{tabular}{|c|c|c|c|c|c|}
\hline \multicolumn{2}{|c|}{ Clinicopathological features } & \multirow{3}{*}{$\begin{array}{l}\begin{array}{l}\text { No. of } \\
\text { cases }\end{array} \\
78\end{array}$} & \multicolumn{2}{|c|}{$\begin{array}{l}\text { miR-9 } \\
\text { expression }\end{array}$} & \multirow[t]{2}{*}{$P$} \\
\hline & & & Low & High & \\
\hline \multirow[t]{2}{*}{ Age (year) } & $<50$ & & 40 & 38 & 0.662 \\
\hline & $\geq 50$ & 122 & 58 & 64 & \\
\hline \multirow[t]{2}{*}{ Gender } & Male & 107 & 53 & 54 & 0.889 \\
\hline & Female & 93 & 45 & 48 & \\
\hline \multirow[t]{2}{*}{ Tumor size } & $<5 \mathrm{~cm}$ & 82 & 36 & 46 & 0.252 \\
\hline & $\geq 5 \mathrm{~cm}$ & 118 & 62 & 56 & \\
\hline \multirow[t]{2}{*}{ Tumor stage } & Early stage (I-II) & 71 & 42 & 29 & 0.0389 \\
\hline & $\begin{array}{l}\text { Advanced } \\
\text { stage (III-IV) }\end{array}$ & 129 & 56 & 73 & \\
\hline \multirow{2}{*}{$\begin{array}{l}\text { Venous } \\
\text { infiltration }\end{array}$} & Absent & 131 & 82 & 49 & $<0.0001$ \\
\hline & Present & 69 & 16 & 53 & \\
\hline \multirow[t]{2}{*}{ AFP level } & $\leq 20 \mathrm{ng} / \mathrm{ml}$ & 45 & 27 & 18 & 0.127 \\
\hline & $>20 \mathrm{ng} / \mathrm{ml}$ & 155 & 71 & 84 & \\
\hline
\end{tabular}

stage of HCC $(P=0.0228$, Figure $3 \mathrm{~b})$ and the advanced HCC $(\mathrm{P}=0.0062$, Figure 3c).

\section{Multivariate Cox proportional hazard analysis}

In the Cox proportional hazard model, it was confirmed that miR-9 expression in the biopsy samples (RR 4.28; 95\% CI, 2.77-7.23), tumor stage (RR 3.10; 95\% CI, 1.22-4.77), and venous infiltration (RR, 2.61; 95\% CI, 1.34-5.12) were predictor of poor prognosis of the patients with HCC. Our results showed that age (RR, 1.60; RR, 0.40-2.65), gender (RR, 1.53; 95\% CI, 0.50-2.95), tumor size (RR, 2.25; 95\% CI, 0.95-4.34), and AFP (RR, 1.38; 95\% CI, $0.58-2.64)$ were not independent predictor of the survival of patients with HCC (Table 2).

\section{Discussion}

Although with the development of early diagnosis and surgical techniques, the patients with hepatocellular carcinoma

Table 2 Multivariate analyses of different prognostic parameters in patients with HCC by Cox regression analysis

\begin{tabular}{llll}
\hline Parameter & Risk ratio $^{\mathbf{1}}$ & $\mathbf{9 5 \% \mathbf { C l } ^ { \mathbf { 2 } }}$ & $\boldsymbol{P}^{\mathbf{3}}$ \\
\hline Age & 1.60 & $0.40-2.65$ & 0.667 \\
Gender & 1.53 & $0.50-2.95$ & 0.754 \\
Tumor size & 2.25 & $0.95-4.34$ & 0.078 \\
AFP & 1.38 & $0.58-2.64$ & 0.430 \\
Venous infiltration & 2.61 & $1.34-5.12$ & 0.006 \\
miR-9 expression & 4.28 & $2.77-7.23$ & $<0.001$ \\
\hline
\end{tabular}

${ }^{1} \mathrm{RR}$; relative risk.

${ }^{2} \mathrm{Cl}$; confidence interval.

${ }^{3} \mathrm{P}$-value, 0.05 statistically significant and significant $\mathrm{p}$-values are in bold. 

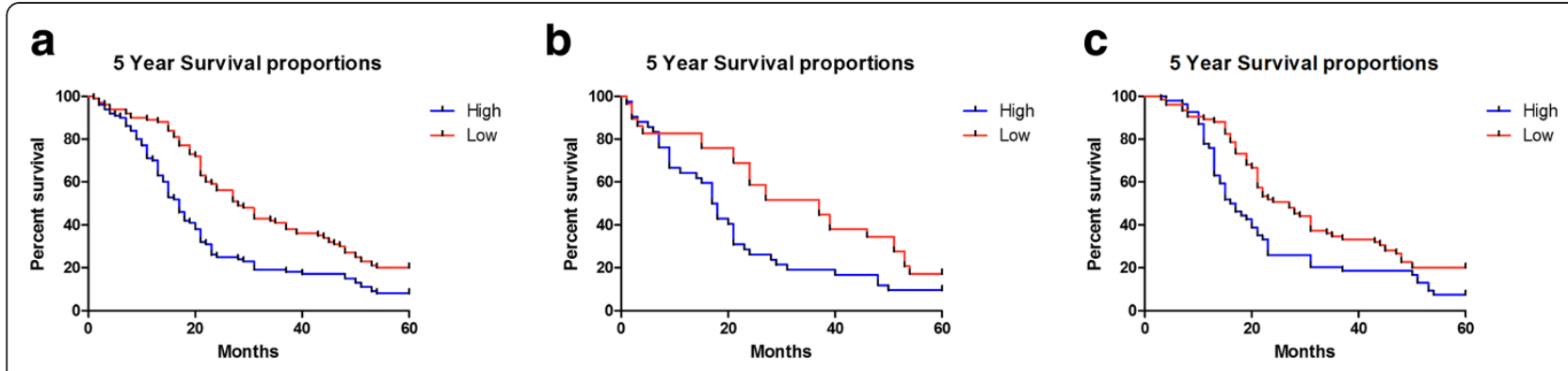

Figure 3 Kaplan-Meier survival curves for HCC patients with high or low expression of miR-9. (a) The 5-year overall survival rate of all 200 HCC patients with high or low miR-9 expression; (b) The 5-year overall survival rate of 71 HCC patients with early stage in high or low miR-9 expression group; (c) The 5-year overall survival rate of 129 HCC patients with advanced stage in high or low miR-9 expression group.

still results with a relatively bad prognosis. The molecular biomarkers for early diagnosis and predictor of prognosis are desperately required now. A lot of work has been conducted in an attempt to identify biomarkers with diagnostic and prognostic implications for HCC. MiRNAs have been demonstrated to be critical regulators of carcinogenesis and tumor progression in HCC. The role of miR-9 as a prognostic factor has been recently described in different tumours, such as acute lymphocytic leukemia [30], acute myeloid leukemia [31], and colon cancer [32]. Similarly in the present study, we observed that miR-9 expression was up-regulated in HCC tissues compared with noncancerous liver tissues. The up-regulation of miR-9 in HCC cancer tissues was also significantly correlated with aggressive clinicopathological features. We found that the patients with high miR-9 expression have an advanced tumor staging and are in higher risk of venous infiltration. Moreover, the results of Kaplan-Meier analyses showed that HCC patients with the high miR-9 expression tend to have shorter overall survival and progression free survival. The multivariate analysis clearly indicated that the high miR-9 expression in biopsy samples may be considered as an independent prognostic factor in HCC for decreased survival.

MiR-9 is a regulator of neuronal progenitor cell fate during neurogenesis $[13,14]$, which has recently been implicated in cancer [15]. Although most studies indicate a tumour-suppressor activity for miR-9 in cancer cells [16], conflicting data exist, and the outcome of miR-9 function appears to be tumour specific [17]. Recent studies also report that miR-9 is heterogeneously expressed within a given tissue [23]. miR-9 is downregulated in breast cancer, renal cell carcinoma, and gastric cancer due to promoter methylation [18-20]. The transcriptional activity of miR-9 seems to be related to gene silencing by DNA methylation. Previous studies have demonstrated that the high frequency of hypermethylated $\mathrm{CpG}$ islands at miR-9 genes resulted in down-regulation of miR-9 in human cancer [20]. In addition, microRNA-9 is a methylation-silenced tumour suppressor that could be a potential candidate predictive marker for poor prognosis of medulloblastoma.
Loss of microRNA-9 may confer a proliferative advantage to tumour cells, and it could possibly contribute to disease pathogenesis [33]. On the other hand, the downexpression of miR-9 may be introduced by hypoxic stress, resulting in alternative splicing shift to proangiogenic isoforms of VEGF165 [34]. However, in contrast, miR9 has been found to be upregulated in various cancer tissues like HCC, gliomas, and colorectal cancer [21,22,35]. Previous study reported miR-9 may possibly promote HCC migration and invasion through regulation of KLF17 [35]. In the present study, the up-expression of the miR-9 demonstrated aggressive clinicopathological features, with the mechanism still unknown. Ma et al. have suggested a regulatory pathway of miR-9 as a metastasis-promoting miRNA [24]. They demonstrated that miR-9 directly targets $\mathrm{CDH} 1$, the E-cadherin- encoding mRNA, leading to down-regulation of E-cadherin and increase in cancer cell motility and invasiveness [24]. Besides induction of Epithelial-mesenchymal transition (EMT), miR-9 was found to contribute to tumor angiogenesis, another important mechanism in metastasis, through activation of beta-catenin signaling pathway induced by E-cadherin down-regulation [24]. Recently, they also showed that miR-9 can function as a metastasispromoting miRNA even in the E-cadherin-negative breast cancer cells through downregulation of leukemia inhibitory factor receptor [36].

\section{Conclusion}

In conclusion, our results have demonstrated that the levels of miR-9 are higher in HCC tissues than those in matched normal liver tissues and correlated with disease stage and the presence of venous infiltration. These findings enhance our understanding of the role of miR-9 in HCC progression and suggest that miR-9 may function as microtumor promoter genes in HCC. These findings suggest the potential clinical use of microRNA measurements, particularly in estimating prognosis for patients with HCC. Large well-designed studies with diverse 
populations and functional evaluations are warranted to confirm and extend our findings. Examining new targets and other biological experiments will clarify the functions and roles of microRNAs in HCC.

\section{Competing interests}

The authors declare that they have no competing interests.

\section{Authors' contributions}

LC designed and carried out the study, and drafted the manuscript. XC participated in the performance of the study and performed the statistical analysis. All authors read and approved the final manuscript.

\section{Author details}

'Department of Hepatobiliary Surgery, Jingzhou First People's Hospital/The First Affiliated Hospital of Yangtze University, No.8 Hangkong Road, Shashi district, Jingzhou 434000, Hubei, China. ${ }^{2}$ Academy Office, Clinical Medical College, Yangtze University, Jingzhou, China.

Received: 4 November 2014 Accepted: 8 December 2014

Published online: 31 December 2014

\section{References}

1. Jemal A, Bray F, Center MM, Ferlay J, Ward E, Forman D: Global cancer statistics. CA Cancer J Clin 2011, 61:69-90.

2. Kiyosawa K, Umemura T, Ichijo T, Matsumoto A, Yoshizawa K, Gad A, Tanaka E: Hepatocellular carcinoma: recent trends in Japan. Gastroenterology 2004, 127:S17-S26

3. Nguyen VT, Law MG, Dore GJ: Hepatitis b-related hepatocellular carcinoma: epidemiological characteristics and disease burden. J Viral Hepat 2009, 16:453-463.

4. Bartel DP: Micrornas: genomics, biogenesis, mechanism, and function. Cell 2004, 116:281-297.

5. Pillai RS: Microrna function: multiple mechanisms for a tiny RNA? RNA 2005, 11:1753-1761.

6. Zamore PD, Haley B: Ribo-gnome: the big world of small RNAs. Science 2005, 309:1519-1524.

7. Bentwich I, Avniel A, Karov Y, Aharonov R, Gilad S, Barad O, Barzilai A, Einat P, Einav U, Meiri E, Sharon E, Spector Y, Bentwich Z: Identification of hundreds of conserved and nonconserved human micrornas. Nat Genet 2005, 37:766-770.

8. Berezikov E, Guryev V, van de Belt J, Wienholds E, Plasterk RH, Cuppen E: Phylogenetic shadowing and computational identification of human microrna genes. Cell 2005, 120:21-24.

9. Lewis BP, Burge CB, Bartel DP: Conserved seed pairing, often flanked by adenosines, indicates that thousands of human genes are microrna targets. Cell 2005, 120:15-20.

10. Hwang HW, Mendell JT: Micrornas in cell proliferation, cell death, and tumorigenesis. Br J Cancer 2006, 94:776-780.

11. Wienholds E, Plasterk RH: Microrna function in animal development. FEBS Lett 2005, 579:5911-5922.

12. Jovanovic M, Hengartner MO: Mirnas and apoptosis: RNAs to die for. Oncogene 2006, 25:6176-6187.

13. Wienholds E, Kloosterman WP, Miska E, Alvarez-Saavedra E, Berezikov E,

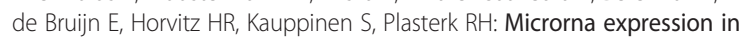
zebrafish embryonic development. Science 2005, 309:310-311.

14. Shibata M, Nakao H, Kiyonari H, Abe T, Aizawa S: Microrna-9 regulates neurogenesis in mouse telencephalon by targeting multiple transcription factors. J Neurosci 2011, 31:3407-3422.

15. Delaloy C, Liu L, Lee JA, Su H, Shen F, Yang GY, Young WL, Ivey KN, Gao FB: Microrna-9 coordinates proliferation and migration of human embryonic stem cell-derived neural progenitors. Cell Stem Cell 2010, 6:323-335.

16. Laios A, OToole S, Flavin R, Martin C, Kelly L, Ring M, Finn SP, Barrett C, Loda M, Gleeson N, D'Arcy T, McGuinness E, Sheils O, Sheppard B, OL J: Potential role of mir-9 and mir-223 in recurrent ovarian cancer. Mol Cancer 2008, 7:35.

17. Khew-Goodall Y, Goodall GJ: Myc-modulated mir-9 makes more metastases. Nat Cell Biol 2010, 12:209-211.
18. Lehmann $\mathrm{U}$, Hasemeier $\mathrm{B}$, Christgen $\mathrm{M}$, Muller $\mathrm{M}$, Romermann $\mathrm{D}$, Langer $\mathrm{F}$, Kreipe H: Epigenetic inactivation of microrna gene hsa-mir-9-1 in human breast cancer. J Pathol 2008, 214:17-24.

19. Hildebrandt MA, Gu J, Lin J, Ye Y, Tan W, Tamboli P, Wood CG, Wu X: Hsa-mir-9 methylation status is associated with cancer development and metastatic recurrence in patients with clear cell renal cell carcinoma. Oncogene 2010, 29:5724-5728.

20. Tsai KW, Liao YL, Wu CW, Hu LY, Li SC, Chan WC, Ho MR, Lai CH, Kao HW, Fang WL, Huang KH, Lin WC: Aberrant hypermethylation of mir-9 genes in gastric cancer. Epigenetics 2011, 6:1189-1197.

21. Malzkorn B, Wolter M, Liesenberg F, Grzendowski M, Stuhler K, Meyer HE, Reifenberger $\mathrm{G}$ : Identification and functional characterization of micrornas involved in the malignant progression of gliomas. Brain Pathol 2010, 20:539-550.

22. Zhu L, Chen H, Zhou D, Li D, Bai R, Zheng S, Ge W: Microrna-9 up-regulation is involved in colorectal cancer metastasis via promoting cell motility. Med Oncol 2012, 29:1037-1043.

23. Bonev B, Pisco A, Papalopulu N: Microrna-9 reveals regional diversity of neural progenitors along the anterior-posterior axis. Dev Cell 2011, 20:19-32.

24. Ma L, Young J, Prabhala H, Pan E, Mestdagh P, Muth D, Teruya-Feldstein J, Reinhardt F, Onder TT, Valastyan S, Westermann F, Speleman F, Vandesompele J, Weinberg RA: Mir-9, a myc/mycn-activated microrna, regulates e-cadherin and cancer metastasis. Nat Cell Biol 2010, 12:247-256.

25. Hu X, Schwarz JK, Lewis JS Jr, Huettner PC, Rader JS, Deasy JO, Grigsby PW Wang X: A microrna expression signature for cervical cancer prognosis. Cancer Res 2010, 70:1441-1448.

26. Tan HX, Wang Q, Chen LZ, Huang XH, Chen JS, Fu XH, Cao LQ, Chen XL, Li W, Zhang L: Microrna-9 reduces cell invasion and e-cadherin secretion in sk-hep-1 cell. Med Oncol 2010, 27:654-660.

27. Guo LM, Pu Y, Han Z, Liu T, Li YX, Liu M, Li X, Tang H: Microrna-9 inhibits ovarian cancer cell growth through regulation of nf-kappab1. FEBS $J$ 2009, 276:5537-5546.

28. Wan HY, Guo LM, Liu T, Liu M, Li X, Tang H: Regulation of the transcription factor nf-kappab1 by microrna-9 in human gastric adenocarcinoma. Mol Cancer 2010, 9:16.

29. Chen TH, Chang SW, Huang CC, Wang KL, Yeh KT, Liu CN, Lee H, Lin CC, Cheng YW: The prognostic significance of apc gene mutation and mir-21 expression in advanced stage colorectal cancer. Colorectal Dis 2013

30. Agirre X, Vilas-Zornoza A, Jimenez-Velasco A, Martin-Subero Jl, Cordeu L, Garate L, San Jose-Eneriz E, Abizanda G, Rodriguez-Otero P, Fortes P, Rifon J, Bandres E, Calasanz MJ, Martin V, Heiniger A, Torres A, Siebert R, Roman-Gomez J, Prosper F: Epigenetic silencing of the tumor suppressor microrna hsa-mir-124a regulates cdk6 expression and confers a poor prognosis in acute lymphoblastic leukemia. Cancer Res 2009, 69:4443-4453.

31. Marcucci G, Radmacher MD, Maharry K, Mrozek K, Ruppert AS, Paschka P, Vukosavljevic T, Whitman SP, Baldus CD, Langer C, Liu CG, Carroll AJ, Powell BL, Garzon R, Croce CM, Kolitz JE, Caligiuri MA, Larson RA, Bloomfield CD: Microrna expression in cytogenetically normal acute myeloid leukemia. N Engl J Med 2008, 358:1919-1928.

32. Schetter AJ, Leung SY, Sohn JJ, Zanetti KA, Bowman ED, Yanaihara N, Yuen ST, Chan TL, Kwong DL, Au GK, Liu CG, Calin GA, Croce CM, Harris CC: Microrna expression profiles associated with prognosis and therapeutic outcome in colon adenocarcinoma. JAMA 2008, 299:425-436.

33. Fiaschetti G, Abela L, Nonoguchi N, Dubuc AM, Remke M, Boro A, Grunder E, Siler U, Ohgaki H, Taylor MD, Baumgartner M, Shalaby T, Grotzer MA Epigenetic silencing of mirna-9 is associated with hes 1 oncogenic activity and poor prognosis of medulloblastoma. Br J Cancer 2014, 110:636-647.

34. Yoon C, Kim D, Kim S, Park GB, Hur DY, Yang JW, Park SG, Kim YS: Mir-9 regulates the post-transcriptional level of vegf165a by targeting srpk-1 in arpe-19 cells. Graefes Arch Clin Exp Ophthalmol 2014, 252:1369-1376.

35. Budhu A, Jia HL, Forgues M, Liu CG, Goldstein D, Lam A, Zanetti KA, Ye QH, Qin LX, Croce CM, Tang ZY, Wang XW: Identification of metastasis-related micrornas in hepatocellular carcinoma. Hepatology 2008, 47:897-907.

36. Chen D, Sun Y, Wei Y, Zhang P, Rezaeian AH, Teruya-Feldstein J, Gupta S, Liang $\mathrm{H}$, Lin HK, Hung MC, Ma L: Lifr is a breast cancer metastasis suppressor upstream of the hippo-yap pathway and a prognostic marker. Nat Med 2012, 18:1511-1517. 